\title{
Penicillin concentrations in cerebrospinal fluid (CSF) during repository treatment regimen for syphilis
}

\author{
P G M VAN DER VALK, * E J KRAAI, * P C VAN VOORST VADER, * \\ H HAAXMA-REICHE, $\dagger$ J A M SNIJDER $\ddagger$ \\ From the Departments of *Dermatovenereology, and $\dagger$ Neurology, University Hospital, and the $\ddagger$ Regional \\ Laboratory of Health, Groningen, The Netherlands
}

SUMMARY Penicillin concentrations in cerebrospinal fluid (CSF) were measured in 40 asymptomatic patients with syphilis, 10 of whom had neurosyphilis. The patients were treated with $2.4 \mathrm{MIU}$ procaine penicillin a day intramuscularly in combination with $500 \mathrm{mg}$ probenecid every six hours orally.

This intramuscular treatment regimen did not consistently yield treponemicidal penicillin concentrations in the CSF (subtreponemicidal CSF concentrations were found in 17 patients, four of whom had neurosyphilis). These data provide additional evidence that the cure of asymptomatic neurosyphilis is not guaranteed by intramuscular penicillin treatment.

The therapeutic approach to neurosyphilis is controversial. Optimum treatment necessitates maintaining continuous treponemicidal penicillin concentrations for a sufficient length of time. It is not clear, however, whether the treponemicidal penicillin concentration of $>0.018 \mathrm{mg} / \mathrm{l}$ recommended by the World Health Organisation is always needed. Current intramuscular penicillin regimens, which do not consistently give treponemicidal cerebrospinal fluid (CSF) penicillin concentrations, appear to be adequate for treating early syphilis, but may be insufficient for late (latent) syphilis. ${ }^{1-3}$

An intramuscular treatment regimen plus oral probenecid, which appeared to produce consistently treponemicidal penicillin concentrations, has been reported. ${ }^{4}$ We report less favourable results from the same regimen.

\section{Patients and methods}

Forty asymptomatic patients with positive syphilis serology test results of unknown duration (for more than a year, with the possible exception of three patients) were admitted to hospital for lumbar puncture and initial treatment. All had positive results

Address for reprints: Dr P C van Voorst Vader, Department of Dermatovenereology, Academisch Ziekenhuis Groningen, PO Box $30.001,9700$ RB Groningen, The Netherlands

Accepted for publication 11 October 1987 to the Treponema pallidum haemagglutination assay (TPHA) and the fluorescent treponemal antibody absorption (FTA-ABS) test. They received 2.4 MIU procaine penicillin a day intramuscularly for 10 days in combination with probenecid $500 \mathrm{mg}$ orally every six hours (their mean (SD) weight was 70.7 (10.5) kg). Lumbar puncture was performed on the second day, after 6,18 , or 24 hours of complete bed rest. The CSF was examined for abnormalities indicating neurosyphilis. The TPHA index and the IgG index were calculated using the following formulas:

TPHA index $=\frac{\text { CSF TPHA titre }}{\text { serum TPHA titre }} \div$ albumin quotient IgG index $=\frac{\text { CSF IgG concentration }}{\text { serum IgG concentration }} \div$ albumin quotient (albumin quotient $\left.=\frac{\text { CSF albumin concentration }}{\text { serum albumin concentration }}\right)$

Neurosyphilis (asymptomatic) was defined by the following CSF findings: a positive result in the TPHA or FTA-ABS test, or both, in combination with a positive result in the Venereal Disease Research Laboratory (VDRL) test, a TPHA index of more

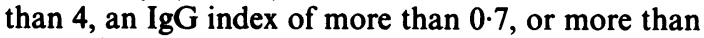
$3 \times 10^{6} / 1$ mononuclear leucocytes. ${ }^{56}$

Penicillin CSF and serum concentrations were measured by a microbiological assay (agar well diffusion) using Sarcina lutea as the test organism. A 
Table Cerebrospinal fluid (CSF) penicillin concentrations during repository treatment regimen in 40 asymptomatic patients with positive results of serology tests for syphilis

\begin{tabular}{|c|c|c|c|c|}
\hline \multirow{2}{*}{$\begin{array}{l}\text { Interval between } \\
\text { intramuscular } \\
\text { injection and } \\
\text { lumbar puncture }\end{array}$} & \multicolumn{2}{|c|}{ Patients with neurosyphilis $(n=10)$} & \multicolumn{2}{|c|}{ Patients with normal CSF $(n=30)$} \\
\hline & $\begin{array}{l}\text { Mean (range) penicillin } \\
\text { concentrations (mg/l) }\end{array}$ & $\begin{array}{l}\text { No with } \\
<0.018 \mathrm{mg} / \mathrm{l}\end{array}$ & $\begin{array}{l}\text { Mean (range) penicillin } \\
\text { concentrations ( } \mathrm{mg} / \mathrm{l})\end{array}$ & $\begin{array}{l}\text { No with } \\
<0.018 \mathrm{mg} / \mathrm{l}\end{array}$ \\
\hline $\begin{array}{l}6 \text { hours }(n=12) \\
18 \text { hours }(n=18) \\
24 \text { hours }(n=10)\end{array}$ & $\begin{array}{l}0.099(0.001-0.198) \\
0.070(0.01-0.15) \\
0.016(0.005-0.026)\end{array}$ & $\begin{array}{l}1 / 3 \\
1 / 3 \\
2 / 4\end{array}$ & $\begin{array}{l}0.150(0.003-0.54) \\
0.289(0.002-2) \\
0.012(0-0.052)\end{array}$ & $\begin{array}{l}3 / 9 \\
5 / 15 \\
5 / 6\end{array}$ \\
\hline
\end{tabular}

*Procaine penicillin 2.4 MIU a day intramuscularly and probenecid $500 \mathrm{mg}$ every six hours orally.

calibration curve was made using horse serum. The lowest CSF concentration detected was $0.001 \mathrm{mg} / 1$. In 30 patients the penicillin concentration in the CSF from the first collecting tube was compared with that in the fifth tube to assess the differences in concentrations at different levels of the central nervous system.

\section{Results}

The table shows the means and ranges of CSF penicillin concentrations and numbers of patients with subtreponemicidal concentrations according to the interval after injection. The serum concentrations were treponemicidal (mean $6.05 \mathrm{mg} / \mathrm{l}$; range $0.3-25$ $\mathrm{mg} / \mathrm{l})$ in all patients. Neurosyphilis was diagnosed in $10 / 40$ patients (10 were positive in the TPHA or FTAABS test or both, six in the VDRL test, six had a TPHA index of more than 4, five had an IgG index of more than 0.7 , and seven had more than $3 \times 10^{6} / 1$ mononuclear leucocytes. These tests gave negative results in the remaining 30 patients. CSF penicillin concentrations of less than $0.018 \mathrm{mg} / 1$ were, however, found in $17 / 40$ patients (mean of 40 patients $0 \cdot 16 \mathrm{mg} / \mathrm{l}$; range $0-2 \mathrm{mg} / \mathrm{l}$ ), four of whom had been diagnosed as having neurosyphilis. Serum penicillin concentrations proved to be a poor predictor of CSF penicillin concentrations (Pearson's correlation coefficient $r=0.65 ; p<0.001)$. Concentrations of penicillin in the first and fifth CSF collecting tubes were highly correlated $(r=0.95, p<0.001)$, which suggests a limited role for the dynamics of the CSF in the penetration of penicillin into the CSF of patients taking rest during treatment. The albumin quotient (which indicated the blood brain barrier function) did not correlate with CSF penicillin concentrations in our patients (mean (SD) albumin quotient $\times 1000$ : 6.38 (3.46), normal <7.80; $\mathrm{r}=-0.47, \mathrm{p}<0.1) .^{146}$ Ten patients had slightly raised albumin quotients, three of whom had neurosyphilis. Body weight negatively correlated with penicillin concentrations in serum $(\mathrm{r}=-0 \cdot 36)$ and CSF $(\mathrm{r}=-0 \cdot 18)$, which was significant for serum $(p<0.05)$ but not for CSF $(\mathrm{p}<0.3)$.

\section{Discussion}

In our study the intramuscular treatment regimen investigated did not consistently give treponemicidal penicillin concentrations in the CSF, either in patients with latent syphilis (normal CSF) or in patients with asymptomatic neurosyphilis. Our data do not agree with the findings of Dunlop et al, ${ }^{4}$ for which we have no explanation. No study except that of Dunlop et al, however, has reported treponemicidal penicillin concentrations consistently in the CSF of adults treated with an intramuscular regimen. ${ }^{78}$

Our data do not favour using this intramuscular penicillin regimen to treat patients with asymptomatic neurosyphilis. Uncertain patient compliance with oral medication and the lack of data on the effect of probenecid on brain parenchyma penicillin concentrations further strengthen this view. ${ }^{9}$

An alternative treatment policy for patients with early and late syphilis without neurological symptoms consists of 7.2 MIU benzathine penicillin G intramuscularly in weekly doses of $2.4 \mathrm{MIU}$, preferably followed by lumbar puncture one or two years later. Patients with symptomatic neurosyphilis, and possibly also patients with relevant persisting residual CSF abnormalities after intramuscular treatment, should be treated with intravenous penicillin. ${ }^{1011} \mathrm{~A}$ treatment regimen of 0.15 MIU per kilogram of body weight given in six equal doses a day for 15 days could be used. ${ }^{12}$ It cannot be excluded that a smaller percentage of patients with syphilis but without neurological symptoms might develop (a)symptomatic neurosyphilis in the follow up period if treated with the intramuscular treatment regimen used in our study rather than the alternative intramuscular regimen mentioned. The risk of developing symptomatic neurosyphilis after intramuscular penicillin treatment appears to be small, however, if treatment is of sufficient duration, even if the regimen used does not give treponemicidal CSF penicillin concentrations. ${ }^{13}$

\section{References}

1 Löwhagen GB, Andersson M, Blomstrand C, Roupe G. Central 
nervous system involvement in early syphilis. Acta Derm Venereol (Stockh) 1983;63:409-17.

2 Jørgensen J, Tikjøb G, Weismann K. Neurosyphilis after treatment of latent syphilis with benzathine penicillin. Genitourin Med 1986;62:129-31.

3 Tramont EC. Syphilis in the AIDS era. [Editorial]. $N$ Engl $J$ Med 1987;316:1600-1.

4 Dunlop EMC, Al-Egaily SS, Houang ET. Production of treponemicidal concentration of penicillin in cerebrospinal fluid. Br Med J 1981;283:646.

5 Stöckli HR. Neurosyphilis heute. Dermatologica 1982;165:232-48.

6 Luger A, Schmidt BL, Steyrer K, Schonwald E. Diagnosis of neurosyphilis by examination of the cerebrospinal fluid. British Journal of Venereal Diseases 1981;57:232-7.

7 Löwhagen GB, Brorson JE, Kaijser B. Penicillin concentrations in cerebrospinal fluid and serum after intramuscular, intravenous and oral administration to syphilitic patients. Acta. Derm Venereol (Stockh) 1983;63:53-7.

8 Dunlop EMC. Survival of treponemes after treatment: comments, clinical conclusions, and recommendations. Genitourin Med 1985;61:293-301.

9 Rein MF. Treatment of neurosyphilis. [Editorial]. JAMA 1981;246:2613-4.

10 van Eijk RVW, Wolters ECh, Tutuarima JA, et al. Effect of early and late syphilis on central nervous system: cerebrospinal fluid changes and neurological deficit. Genitourin Med 1987;63: 77-82.

11 Prange HW, Moskophidis M, Schipper HI, Müller F. Relationship between neurological features and intrathecal synthesis of IgG antibodies to Treponema pallidum in untreated and treated human neurosyphilis. J Neurol 1983;230:241-52.

12 Schoth PEM, Wolters ECh. Penicillin concentrations in serum and CSF during high dose intravenous treatment for neurosyphilis. Neurology 1987;37:1214-6.

13 Perdrup A, Jørgensen BB, Pedersen NS. The profile of neurosyphilis in Denmark. Acta Derm Venereol (Stockh) 1981;suppl 96:3-14. 